\title{
Epidemiological Study of Injuries Arising from Karting Competition in Children
}

\author{
Delmuns Salvi ${ }^{1}$, Roig Marc ${ }^{2}$, Javierre Casimiro ${ }^{3}$, Mans Cristina ${ }^{4}$ and Giné-Garriga Maria ${ }^{1,5 *}$ \\ ${ }^{1}$ Faculty of Health Sciences Blanquerna. Ramon Llull University, Barcelona, Spain \\ ${ }^{2}$ Department of Exercise and Sport Sciences, University of Copenhagen, Denmark \\ ${ }^{3}$ Faculty of Medicine. Universitat de Barcelona, Spain \\ ${ }^{4}$ Roca i Pi Legacy Foundation, Barcelona, Spain \\ ${ }^{5}$ Faculty of Psychology, Education and Sport Sciences Blanquerna. Ramon Llull University, Barcelona, Spain
}

\section{Abstract}

Objective: The main aim was to define the impact and type of injuries in children aged from 7 to 15 years old competing in karting competition in Catalonia during the 2005-2009 periods. Secondary aims were to analyze the differences in injuries according to year of competition, category, number of participants and circuit. We also explored risk factors for injury and suggest possible corrective measures to reduce its number and severity.

Design: Longitudinal epidemiological study with retrospective data. The study period was the 5 -year period from 2005 to 2009

Setting: The study took part in 6 karting circuits in Catalonia.

Patients and methods: A total of 334 licensed drivers who participated in the Catalan Karting Championship. The subjects were in the age range from 7 to (and including) 15 years old with an average drive age of 11 years old.

Results: Three hundred and thirty four drivers completed a total No. of $445590.8 \mathrm{~km}$ of competition and 38 of them sustained injuries during the 5 years of the study. Corporal injuries were mainly, located in hands and wrists (42.1\%) followed of injuries in thorax and elbow (13.1\%). In the years 2005 and 2007, as well as in circuits located in Sils, Mora and Juneda, significant differences were found in the number of drivers injured in relation to the number of participations.

Conclusions: The low injury incidence suggests that Karting is a relatively safe sport. The fact that injuries were mainly produced in specific bodily regions emphasizes the importance of protecting them to reduce the risk of injury. A more in depth analysis is required to explain why injuries occurred preferentially in some circuits and in some specific competition years.

Keywords: Injuries; Karting; Competition; Epidemiology; Risk of injury; Children

\section{Introduction}

Competition karting is a type of four-wheel motorsport where children compete from a very early age [1]. Competition karting has been the initial training sport for many current F1 Spanish drivers.

In Spain construction of karting circuits started in the 1950s, with basically two types of use: for rent (internationally known as 'Go-Kart') and for competition. A very important difference between the two is that in order to compete in karting, drivers need to be federated.

Competition regulations require drivers to use safety equipment such as a cervical collar, a chest protector, fire retardant clothing, and roll bars on the karts [2-7]. These items, which must be officially approved and technically verified by race marshals, are always suited to the specific size of each driver. The seat and pedals also adjust ergonomically and may be adapted according to the height and driving position of the child or adolescent driver [7]. The objective of these passive safety elements is to prevent injuries and minimise their extent in the event of an accident.

Epidemiological studies of injuries from Go-Kart have been conducted, but there are no known studies on competition karting. Eker et al. published a study detailing the injury mechanisms suffered by 600 karting practitioners in The Netherlands during a specific year [8]. In 2002 a study of cases that needed emergency care in Hong Kong showed that accidents on outdoor tracks appeared to be more serious and more likely to occur than those on indoor circuits [9].

Whitfield et al. published a case study that gathered information about injuries derived from 'Go-Kart' and 'Fun Kart' [10]. In the same year of publication, Adler et al. conducted a study into the risk factors involved in 'Go-Kart' and 'Fun Kart' concluding that hitting a stationary object or a moving vehicle was the most frequent hazard pattern followed by tip-over incidents. The analysis of injury and death data showed that a majority of injured children were between the ages of 8 and 14 years old [11].

Various publications exist on the injuries sustained in 'Go-Karting' [12-17]. Kim et al. and Levesque et al. analysed respiratory injuries caused by the high concentration of carbon dioxide in indoor karting circuits $[18,19]$

It is important to note that none of the studies differentiates between competitive karting and 'Go-Kart'. It also needs to be stressed that no official competitions take place in indoor circuits, except in some federations in Scandinavian countries [18-25].

Taking into account the scant evidence specific to competition

*Corresponding author: Maria GinéGarriga (PhD, PT), Faculty of Psychology, Education and Sport Sciences Blanquerna. Ramon Llull University, Barcelona, Spain, Tel: 0034629589215; E-mail: mariagg@blanquerna.url.edu

Received June 05, 2014; Accepted July 25, 2014; Published July 30, 2014

Citation: Delmuns S, Roig M, Javierre C, Mans C, Maria GG (2014) Epidemiological Study of Injuries Arising from Karting Competition in Children. J Community Med Health Educ 4: 301. doi:10.4172/2161-0711.1000301

Copyright: ( 2014 Delmuns S, et al. This is an open-access article distributed under the terms of the Creative Commons Attribution License, which permits unrestricted use, distribution, and reproduction in any medium, provided the original author and source are credited. 
karting on the basis of federative regulations, the main objective of this study is to understand the type and severity of injuries sustained in competition karting during the 2005-2009 period in Catalonia. The secondary objective is to disseminate results about the circuits and categories in which most injuries were sustained.

\section{Materials and Methods}

\section{Study population}

A longitudinal epidemiological study with retrospective data was carried out on drivers and traumatic injuries recorded in medical reports and official documentation of the Catalan Automobile Federation (FCA).

The sample was based on the population of yearly licensed, federated drivers who competed and participated in the Karting Championship of Catalonia between 2005 and 2009. The sample consisted of 334 drivers ranging from 7 up to and including 15 years of age (with an average driver age of 11). It was calculated that an average of $179.3 \mathrm{~km}$ was covered per driver. Drivers, who raced in the youngest category start at age 7 to 8 , only competed in the 2009 season.

The study was approved by the ethics committee of the FCA, as well as by the ethical committee of the Universitat Internacional de Catalunya. The parents or legal guardians of the drivers signed an informed consent form that included all of the pertinent information on the study.

\section{Procedure}

The administrative team of the FCA, who was not involved in the study, revised the written records of all the races from the last five years in order to obtain the exact number of participants in each championship race per year. Using this information, an average number of participants for each category, circuit and year was calculated. The number of laps and total kilometres driven by each driver for each race and each championship was also calculated.

Information about the injuries for each driver involved in an accident was collected from the medical records, as well as from the reports from the race directors, which recorded the following information: circuit where the accident happened, category, kart number and federation licence number of the year of competition.

Injuries were later classified according to the validated guidelines provided by the Orchard Sports Injury Classification System (OSICS-10) [26]. This classification uses a four-character code assigned to each injury. The first character relates to the anatomical location of the injury. The second character, to the specific type of injured tissue, and the third and the fourth characters determine the exact joint or organs affected.

\section{Statistical Analysis}

The number of races that drivers participated in was the total of the times that each driver competed on the track, and the number of drivers was the total number of drivers who participated in one or more races. Firstly, a general descriptive analysis was carried out on the sample, taking into account the distribution of the participants and the drivers per competition year, categories and circuits in the 5-year period of the study. The results of the general descriptive analysis were presented in absolute numbers, percentages or averages and standard deviations (SD).

The ratio of incidence of injuries (injury risk) was calculated for each year of competition, based on the number of injuries divided by the total number of drivers/races.

In order to explore possible differences in the general distribution of injured drivers per year, categories and circuits, the Chi-squared test was used.

Given that the majority of drivers changed their category every two years, an annual stratified statistical analysis was used. First a descriptive analysis per year of competition was shown, similar to that described earlier, with the following variables: number of drivers, number of times drivers participated in races, kilometres covered and number of injured drivers. The number of times drivers raced on different circuits was also included.

Subsequently a stratified descriptive analysis was conducted, taking into account the number of drivers and number of times they participated, as well as the average kilometres driven, number of races and the drivers injured in each category and at each circuit. In order to explore possible relationships between the variables and the risk of injury in each year of competition, a binary regression model was generated with those injured and uninjured, as a binary dependent variable. The results of this stratified analysis are presented with measurements of relative risk (RR), with confidence intervals of $95 \%$ (CI 95\%).

In order to determine the annual differences in the number of kilometres and races completed between injured drivers and uninjured drivers, the Mann-Whitney $U$ test was used. In all of the analyses, statistical significance was established at $\mathrm{p}<0.05$.

\section{Results}

A total of 334 subjects completed a total of 445590.8 kilometres of competition and 38 drivers were injured during the five years of the study. The injury risk rates found in Catalonia were lower in relation to the RR (CI 95\%) found ranging from 0.001 to 0.02 .

A greater distribution of injuries to hands and wrists (42.1\%) was found, followed by injuries to the chest and elbow (13.1\%). In terms of the types of injuries, $43.7 \%$ of the injuries to the wrist and hand were wrist sprains, whilst $40 \%$ of the injuries to the chest were ecchymos is over the sternum. This meant that the driver was able to quickly join the next competition, as noted in the FCA's results reports. The most serious injuries were fractures suffered by drivers in the junior category (the oldest group).

According to the secondary objectives, Tables 1, 2 and 3 show the average number of races participated in, number of races and kilometres by year, by category and by circuit, respectively. Table 4 shows the differences between injured and uninjured drivers by number of races and kilometres completed.

Significant differences were found for 2005 and 2007 and for the

\begin{tabular}{|l|c|c|c|c|}
\hline Year & $\mathbf{2 0 0 5}$ & $\mathbf{2 0 0 6}$ & $\mathbf{2 0 0 7}$ & $\mathbf{2 0 0 9}$ \\
\hline Average number of races participated in & $32.3(20.3)$ & $50.1(33.7)$ & $55(34.3)$ & $56.3(35.3)$ \\
\hline Average number of races & $7.3(2.4)$ & $6.9(2.5)$ & $4.5(1.5)$ & $4.5(1.5)$ \\
\hline Average number of kilometres & $225.9(79.8)$ & $208.2(83.8)$ & $140.7(56.7)$ & $162.6(274.1)$ \\
\hline
\end{tabular}

Table 1: Average number of races participated in, number of races and kilometres by year. Data presented in absolute numbers and (SD). 


\begin{tabular}{|l|c|c|c|}
\hline Category & Child (benjamín) & Juvenile (alevín) & Cadet (cadete) \\
\hline Average number of races participated in & $47.3(32.3)$ & $27.9(33.9)$ & $49.4(29.9)$ \\
\hline Average number of races & $5.8(1)$ & $6.1(2.3)$ & $5.6(2.4)$ \\
\hline Average number of kilometres & $149.9(33.8)$ & $167(69.8)$ & $5.9(2.4)$ \\
\hline
\end{tabular}

Table 2: Average number of races participated in, number of races and kilometres by category. Data presented in absolute numbers and (SD).

\begin{tabular}{|l|c|c|c|c|c|}
\hline Circuit & Vendrell & Mora & Osona & Sils & Sallent \\
\hline Average number of races participated in & $39.4(23.4)$ & $49.2(34.1)$ & $48(31.6)$ & $50.2(33.8)$ & $51.57(36.1)$ \\
\hline Average number of races & $5.2(2.5)$ & $5.8(2.2)$ & $6(2.4)$ & $5.8(2.6)$ & $6.2(2.4)$ \\
\hline Average number of kilometres & $154.4(80.8)$ & $174(73.4)$ & $178.8(80)$ & $174.8(83.3)$ & $220(294.8)$ \\
\hline
\end{tabular}

Table 3: Average number of races participated in, number of races and kilometres by circuit. Data presented in absolute numbers and (SD).

\begin{tabular}{|c|c|c|c|}
\hline Variables & Injured & Uninjured & Difference in averages (Cl95\%) \\
\hline Km & $197.8(86.4)$ & $153.6(107.4)$ & $44.1(-20.7,108.9)$ \\
\hline Races & $6.5(2.5)$ & $4.9(3.4)$ & 0.19 \\
\hline
\end{tabular}

Table 4: Differences between injured and uninjured drivers by number of races and km completed. The results are presented as an average, (SD) and differences of the averages with $\mathrm{Cl} 95 \%$

Sils, Móra and Juneda circuits in the number of drivers injured in relation to the number of times they participated in races.

It was found that in 2006 the number of injuries did not increase in relation to the increase in participants. In 2005 and 2007 the Chisquared test results showed a significant difference $(p=0.026)$ in the distribution of injured drivers per competition year, and these two years were the ones in which, proportionally, more drivers suffered an injury in relation to the number of races participated in.

Regarding the total number of races participated in per category in the five years of the study; the cadets' category participated in the highest number of races and also had the largest number of injured drivers. The 6 drivers who had a multiple accident in 2007 were $37.5 \%$ of the total cadets injured in the five years of the study. The junior category start at age 13 to 15 , with 725 numbers of races participated in and 16 injured drivers, was the second most-injured category. 2005 was the year in which 7 juniors were injured, that is, $43.7 \%$ of the total juniors injured in the 5 -year period. The youngest category start at age 7 to 8 , registered a total of 12 number of races participated in, with no injured drivers. This category started to operate in 2009. Significant results were found that related a higher number of injuries in older categories $(\mathrm{p}=0.013)$.

Regarding the circuits, the results of the Chi-squared test showed a significant difference $(\mathrm{p}=0.015)$ in the distribution of injured drivers by circuit in relation to the number of participants. The sils circuit had the highest number of injured drivers, and 481 races participated in. Six of those injured sustained their injuries in the multiple cadet accident in 2007. The Mora circuit recorded the second highest number of injured drivers. This circuit held the highest numbers of races during the period of the study, as two races a year were held, except in 2009. This circuit also had the highest number of races participated in. The circuit that recorded the lowest number of races participated in was the Juneda circuit, with 98 . It held races only in 2009, with 5 injured, and had the lowest prevalence of injuries in the study (5.1\%).

\section{Discussion}

The main findings of the study are: (a) the 334 drivers completed a total of 445590.8 kilometres of competition and 38 drivers were injured during the five years of the study; (b) the average incidence of injury risk in the five years showed that a driver had to participate in 50 races before injuring themselves 0.7 times; (c) the greatest distribution of injuries were found in hands and wrists; and (d) the highest incidence of injury found in relation to years, drivers and races was in 2007, with
1.4 injuries every 50 races, on the assumption that the driver had a constant trajectory.

This study provides the first distribution of injuries by body area specific to competition karting. Of a total of 38 injured drivers, $42.1 \%$ sustained injuries to the wrist and hand (W). This was the part of the body with the highest injury rate, specifically wrist strains, with 7 injured drivers. Impacts from the steering wheel of the kart were likely to have caused these injuries. Karts do not have power steering, and the steering wheels are often designed with a central blade that connects the outer circle with the steering axle. This piece of information could be useful for the manufacturers in order to improve passive safety items.

Injuries to the chest $(\mathrm{C})$ were rated as the second most common injury (13.1\%), with the steering wheel being possibly the device that caused the injury to this part of the body, as karts have no means of fastening the body to the seat. Drivers are obliged by the rules to wear chest protectors. These protectors possibly minimised injuries to the chest, as ecchymosis and hematomas were the injuries classified in our study. No fractures to the ribs or sternum were recorded.

The same number of drivers (13.1\%) had injuries relating to the elbow (E). This joint is the most exposed in the driving position, as it is at the driver's sides and injuries are caused by impacts with other karts. The use of elbow protectors (not compulsory under the applicable regulations) and reinforcement to this area in the racing overalls could be the reason for elbow injuries having been minimised. $80 \%$ of the injuries were hematomas to soft tissue and $20 \%$ cuts or injuries. Previous studies have analysed the injury mechanisms and types of injuries from the practice of 'Go-Kart' (9-11), but none of them analysed injuries from competition, and all of their samples included population of varying ages.

The studies published (9-18) found that injuries sustained in 'GoKart' are more serious than those found in the present study focused in competition karting. Further studies are needed, on the same age groups and the same vehicles, to confirm these differences. The use of officially approved passive safety materials, obligatory for competition drivers, is likely to change the body regions injured and minimise injuries in cases of accident, unlike for those who practice 'Go-Kart'.

It was found that injured drivers drove more kilometres and averaged more races than those who were uninjured. Based on the results of the Mann-Whitney $U$ test, no statistically significant results were found. This tendency can probably be explained by considering that the risk of injury is greater the more competition kilometres are 
completed due to driver-fatigue, which thus increases the possibility of an accident. However, once injured, these injuries are not serious and allow the driver to return to competition in the short term. The differences in the distribution of injuries, in relation to the different categories, were not statistically significant $(\mathrm{p}=0.133)$.

The fact that those in the junior category had a higher number of injuries could be due to the higher level of competition, using faster karts and competing at higher speeds.

The circuit that recorded the lowest number of races participated in was the Juneda circuit, with 98. It held races only in 2009, with 5 injured, and had the lowest prevalence of injuries in the study. After reviewing the reports from the race director, the medical records and the timing sheet, no reasons were found to justify the number of injured drivers in the two races of the first year of Juneda being included in the championship.

The difficulty in measuring accidents in competition is one of the important limitations of this type of study, as it can be affected by various factors (e.g., weather conditions, situations in which the drivers are more likely to have an accident, such as track exits, or conflict points in the circuits).

In the specific case of epidemiological studies in other sports, injury risk is related to 1000 hours of driving. This is the limitation of this study, as it was not possible to measure the number of hours spent by each driver in private practice, free training and the specific number of kilometres covered in these. The results of this study are based on the total kilometres covered in competition of a number of laps in each Catalan Championship race.

Another limitation is the lack of records of detailed information about each accident in which a driver is injured (part of circuit, in a group, alone, lap number, etc.). The improvement of the recordingkeeping systems and the standardisation of those systems would enable researchers to carry out studies to obtain additional key data and findings that would provide information to improve safety issues.

On the basis of this limitation, race record-keeping templates are being developed jointly with the FCA. This is one of the study's contributions in order to generate more thorough databases in the short term.

\section{Conclusion}

The greater distribution of body injuries was found to hands and wrists, followed by injuries to the chest and elbow. This new distribution could be a useful point of reference for manufacturers to develop and improve passive safety elements.

Injury risk rates in Catalonia have been found to be low based on the RR (CI 95\%) found. These results should be compared with future studies in order to determine whether they are high or low with participants of the same ages and similar number of kilometres driven in competitions.

\section{References}

1. Sanches JD (2007) The karting manual: the complete beginner's guide to competitive kart racing. Sparkford: Haynes 2.

2. Comissió Karting (2005) ReglamentEsportiu i Tècnic del Campionat de Catalunya de Karting

3. Comissió Karting (2006) ReglamentEsportiu i Tècnic del Campionat de Catalunya de Karting.

4. Comissió Karting (2007) ReglamentEsportiu i Tècnic del Campionat de Catalunya de Karting.
5. Comissió Karting (2008) ReglamentEsportiu i Tècnic del Campionat de Catalunya de Karting

6. Comissió Karting (2009) ReglamentEsportiu i Tècnic del Campionat de Catalunya de Karting.

7. CIK-FIA (ComissionInternationale de Karting) (2009) Homologations Regulations.

8. Eker HH, Van Lieshout EM, Den Hartog D, Schipper IB (2010) Trauma mechanisms and injuries associated with go-karting. Open Orthop J 4: 107110.

9. CP Ng, CH Chung (2005) Go-kart related injuries: a local scene. Hong Kong Journal of Emergency Medicine 12: 1.

10. Whitfield TW (1998) Go-Kart/Fun-Kart Related Injuries and Deaths, 1985-1996. Consumer Product Safety Commission.

11. Adler P (2000) Go-kart related injuries and deaths to children. Consumer Product Safety Commission.

12. Govaert MJ, Ponsen KJ, de Jonge L, de Wit LT, Obertop H (2001) Fracture of the pancreas in two patients after a go-kart accident. HPB (Oxford) 3: 3-6.

13. Li JCM, Leong HT (2006) Go-kart injuries of the abdominal cavity. Surgical Practice 10: 41-44.

14. Freeman BJ, Feldman A, Mackinnon J (1994) Go-kart injuries of the shoulder region. Injury 25: 555-557.

15. Heddle RM, Robb WA (1974) Go-kart injuries of the urethra. J R Coll Surg Edinb 19: 310-312

16. Bley T, Gahr RH (2002) [Risks and injuries of go-karting]. Zentralbl Chir 127: 523-526.

17. Ahmad M, Sinha P, Al-Tamimi YZ, Sylvester D, Dezso A, et al. (2011) The Isadora syndrome: a case report of cervical, oesophageal and tracheal transection in a go-karting accident. Br J Neurosurg 25: 310-312.

18. Kim T, Wagner J (2010) PM2.5 and CO concentrations inside an indoor go-kart facility. J Occup Environ Hyg 7: 397-406.

19. Lévesque B, Bellemare D, Sanfaçon G, Duchesne JF, Gauvin D, et al. (2005) Exposure to carbon monoxide during indoor karting. Int $\mathrm{J}$ Environ Health Res 15: $41-44$

20. Federación Española de Automovilismo (FEA) (2009) Informe FEA Karting.

21. Federación Española de Automovilismo (FEA) (2008) Informe FEA Karting.

22. Federación Española de Automovilismo (FEA) (2007) Informe FEA Karting.

23. Institute For Motor Sport Safety (2005) A Driver's Guide to Safe Motor Sport. FIA.

24. FIA (2009) The Guide' Anti-Doping Guide for Drivers.

25. Comissió Karting FCA editor (2012) ReglamentEsportiu i Tècnic de Campionatde Catalunya de Karting.

26. Rae K, Orchard J (2007) The Orchard Sports Injury Classification System (OSICS) version 10. Clin J Sport Med 17: 201-204. 